\title{
FORMATION OF TRANSITION PHASES ON INTERFACE BETWEEN MONOCRYSTALLINE Fe AND CU DUE TO MUTUAL SOLID-STATE DIFFUSION
}

Interdiffusion between $\mathrm{Fe}$ (Armco) and $\mathrm{Cu}$ single crystals of similar orientation (around [110]) annealed at temperatures of 873 and $973 \mathrm{~K}$ in air for 0.5 up to $4 \mathrm{~h}$ is studied. Formation of three phases different in their chemical composition has been observed: 1) oxide layer on $\mathrm{Cu}$ border (porous), 2) a layer rich in copper, iron and oxygen, 3) a layer of iron and oxygen with only small addition of $\mathrm{Cu}$. All reactions of interface formation occurred in solid state. It was noted that oxygen plays an important role in development of new phases. Strong Kirkendall effect is observed due to large difference in diffusion coefficients of copper atoms to iron, $\mathrm{D}_{\mathrm{Cu} \rightarrow \mathrm{Fe}}=300 \exp (-67800 / \mathrm{RT})$ and iron atoms to copper $\mathrm{D}_{\mathrm{Cu} \rightarrow \mathrm{Fe}}=0.091 \exp (-46140 / \mathrm{RT})$.

Keywords: copper single crystal, iron single crystal, transition phases, solid-state diffusion

\section{Introduction}

The analysis of Fe-based system with respect to dissolution of various elements is studied since fourties of the previous century [e.g. 1,2] and later [3-8]. It was observed, that diffusivities of elements is different in paramagnetic and ferromagnetic state; for example diffusivity of copper in polycrystalline iron is $\mathrm{D}_{\mathrm{Cu} / \mathrm{Fe}}=0.57 \exp (-57000 / \mathrm{RT})\left(\mathrm{cm}^{2} / \mathrm{s}\right)$ in temperature range $800-1050^{\circ} \mathrm{C}$ and $\mathrm{D}_{\mathrm{Cu} / \mathrm{Fe}}=0.47 \mathrm{exp}(-$ $58380 / \mathrm{RT})\left(\mathrm{cm}^{2} / \mathrm{s}\right)$ in temperature range $650-750^{\circ} \mathrm{C}[9]$. A bit different results are given by Salje et al. in [6]: $\mathrm{D}_{\mathrm{Cu}}$ ${ }_{\gamma \mathrm{Fe}}=0.19 \exp (-65100 / \mathrm{RT})$ and $\mathrm{D}_{\mathrm{Cu} / \mathrm{Fe}}=300 \exp (-67800 / \mathrm{RT})$ $\left(\mathrm{cm}^{2} / \mathrm{s}\right)$. The values of diffusivity of iron in copper are also reported in other papers $[7,8]$. For the sake of clarity, data on diffusion coefficient in $\mathrm{Fe}-\mathrm{Cu}$ system are collected in Table 1. Even though the papers [6-8] discuss the diffusion coefficients that vary strongly, it may be caused by the fact that authors deal with annealing of thin evaporated layer on monocrystalline metallic substrate [6,7], thus the differences in $\mathrm{D}_{\mathrm{Cu} / \mathrm{Fe}}$ and $\mathrm{D}_{\mathrm{Fe} / \mathrm{Cu}}$ may be caused by anisotropy. It is also worth noting that precise orientation of the substrate single crystals is not mentioned. Anyway, the obtained concentration-penetration curves are monotonic [6-9], only Anand et al. [9] show change of temperature dependence of diffusivity of copper in iron.

On the contrary quite different experimental results are obtained while annealing bulk iron and copper single crystal below Curie temperature. Various layers of mentioned elements are formed, where mutual diffusion coefficients play important role in their development. In the following paper, a very important role is additionally played by oxygen. Since the $\mathrm{Fe}-\mathrm{Cu}$ phase diagram does not indicate formation of any phases, the formed phases must be formed as a result of interaction with oxygen. Thus, the literature data regarding diffusion coefficient of oxygen into $\mathrm{Fe}$ and $\mathrm{Cu}$ are given in Table 2 and 3.

In literature there is lack of described experiments on bulk single crystals. In couple of phases, the monocrystalline layer was of few-micrometers thickness, which is not sufficient to observe fully mutual interdiffusion of the metals.

TABLE 1

Diffusion coefficients of in $\mathrm{Cu}-\mathrm{Fe}$ system

\begin{tabular}{|c|c|c|c|c|}
\hline \hline $\mathrm{D}_{\mathrm{Cu} \rightarrow \mathrm{Fe}}\left[\mathrm{cm}^{2} / \mathrm{s}\right]$ & $\mathrm{D}_{\mathrm{Cu} \rightarrow \mathrm{Fe}}\left[\mathrm{cm}^{2} / \mathrm{s}\right]$ & Temp. & $\begin{array}{c}\text { Magnetic } \\
\text { characteristics of Fe }\end{array}$ & Author \\
\hline $0.57 \exp (-57000 / \mathrm{RT})$ & & $1073-1323 \mathrm{~K}$ & Ferromagnetic & Anand, Agarwala[9] \\
\hline $0.47 \exp (-58380 / \mathrm{RT})$ & & $923-1023 \mathrm{~K}$ & Paramagnetic & Anand, Agarwala[9] \\
\hline $0.19 \exp (-65100 / \mathrm{RT})$ & $0.504 \exp (-49740 / \mathrm{RT})$ & $1073-1323 \mathrm{~K}$ & Ferromagnetic & $\begin{array}{c}\text { Salje, Feller-Kniepmeier } \\
{[6,7]}\end{array}$ \\
\hline $300 \exp (-67800 / \mathrm{RT})$ & $0.091 \exp (-46140 / \mathrm{RT})$ & $923-1073 \mathrm{~K}$ & Paramagnetic & $\begin{array}{c}\text { Salje, Feller-Kniepmeier } \\
{[6,7]}\end{array}$ \\
\hline & $1.4 \exp (51800 / \mathrm{RT})$ & $923-1348 \mathrm{~K}$ & Ferromagnetic & Mackliet [8] \\
\hline
\end{tabular}

\footnotetext{
* AGH UNIVERSITY OF SCIENCE AND TECHNOLOGY, FACULTY OF NON-FERROUS METALS, AL. MICKIEWICZA 30, 30-065 KRAKÓW, POLAND

\# Corresponding author: mperek@agh.edu.pl
} 
Diffusion coefficients of oxygen in iron

\begin{tabular}{|c|c|c|c|}
\hline \hline $\mathrm{D}_{\mathrm{O} \rightarrow \mathrm{Fe}}\left[\mathrm{m}^{2} / \mathrm{s}\right]$ & Temp. & Magnetic characteristics of Fe & Author \\
\hline $1.30 \times 10^{-4} \mathrm{exp}\left[-166\left(\mathrm{~kJ} \cdot \mathrm{mol}^{-1}\right) \mathrm{RT}\right]$ & 1223 to $1373 \mathrm{~K}$ & Ferromagnetic & Takadaet al. [10] \\
\hline
\end{tabular}

TABLE 3

Diffusion coefficients of oxygen in copper

\begin{tabular}{|c|c|c|}
\hline \hline $\mathrm{D}_{\mathrm{O} \rightarrow \mathrm{Cu}}\left[\mathrm{m}^{2} / \mathrm{s}\right]$ & Temp. & Author \\
\hline $1.14 \times 10^{-6} \exp (-65200 / \mathrm{RT})$ & $823-1273 \mathrm{~K}$ & Magnusson-Frisk [11] \\
\hline
\end{tabular}

\section{Experimental method}

Single crystals of copper (99.999 at.\%) and Armcoiron (99.995 at.\%) were chosen for the experiment. They represented two different crystal lattices, FCC for copper, and $\mathrm{BCC}$ for iron. The copper single crystals were grown by modified Bridgman technique in graphite crucibles in vacuum better than $10^{-6} \mathrm{~Pa}$. Iron single crystals were produced by strain annealing technique. Copper single crystals had square cross-section $4 \times 4 \mathrm{~mm}$, while iron had circular one, $4 \mathrm{~mm}$ in diameter; pieces of length of about $5 \mathrm{~mm}$ were cut out of the large single crystalline rods. The cut single crystals pieces were etched in order to remove the deformation layer formed as a result of mechanical polishing: $\mathrm{Cu}$ single crystals in diluted $\mathrm{HNO}_{3}, \mathrm{Fe}$ in diluted $\mathrm{H}_{2} \mathrm{SO}_{4}$ with $\mathrm{HCl}$. The single crystals were put in a holder as it is shown in Figure 1 , and screwed by hand with force of about $20 \mathrm{~N}$ to assure good connection during heat treatment. Then the holder with a specimen was introduced into a furnace. The annealing process took place in air; the chosen temperatures were $873 \mathrm{~K}$ or $973 \mathrm{~K}$ and the time was 0.5 to $4 \mathrm{~h}$.

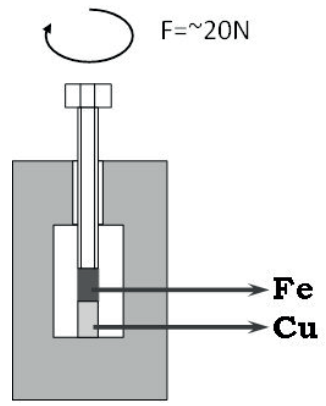

Fig.1. Schematic drawing of a holder used in experiment

The initial orientation of the single crystals was determined from pole figures obtained at Bruker D-8 Advanced X-ray diffractometer: copper was analyzed with copper tube while iron with Co tube. The crystallographic orientation of interface surfaces was $\{011\}$ and 9 degrees of $\{011\}$ in case of copper and iron single crystals, respectively.

The received connections were observed at Hitachi S-3400N scanning electron microscope (SEM) equipped with Energy Dispersive X-ray Spectroscopy (EDS) produced by Thermo. The applied accelerating voltage was $20 \mathrm{keV}$. The polished surface of the connection (final polishing with colloidal silica) was observed by means of backscattered electrons and the EDS point analysis, line-scans through diffusion zone and surface analyses were performed.

\section{Discussion}

In the previous experiments the evaporated layer of a metal was rather thin: $4 \mu \mathrm{m}$ of copper [6], $0.1 \mu \mathrm{m}$ of copper [9] or 1.5-3 $\mu \mathrm{m}$ of iron [7]. Here, it is observed that thickness of interaction layer is even $50 \mu \mathrm{m}$ (Fig. 2b). Even at the lowest temperature and the shortest annealing times the diffusion layer is larger than the evaporated layer described in [6-7]. Besides, the times applied in the experiments described in this paper are much shorter than those found in literature. Thus, it is thought that oxygen enhances the formation of connection.

During annealing of copper and iron single crystals in air a diffusion zone is formed. The morphology of such an interface is complex: it is always composed of at least one layer of solid solution of $\mathrm{Fe}, \mathrm{O}$ and small amount of $\mathrm{Cu}$ (up to 3 at.\%), additionally, usually a layer of transition phase made of $\mathrm{Cu}, \mathrm{Fe}$ and $\mathrm{O}$ (light gray phase in Figs. 2a and 3a,b) is formed. The total depth of a diffusion zone varies with time and temperature of annealing from 5 to $10 \mu \mathrm{m}$ in case of a $\mathrm{Cu}-\mathrm{Fe}$ stack kept at temperature of $873 \mathrm{~K}$ for $0.5 \mathrm{~h}$, to about $50 \mu \mathrm{m}$, when the stack was kept at that temperature for $4 \mathrm{~h}$. In case of temperature of $973 \mathrm{~K}$ the zone has depth of about $10 \mu \mathrm{m}$ for $0.5 \mathrm{~h}$ to $27-40 \mu \mathrm{m}$ for $3 \mathrm{~h}$ of annealing (Figs. 2 and 3).
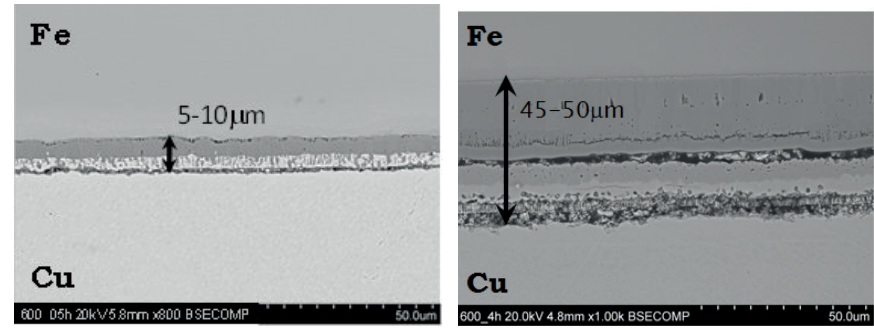

Fig.2.Transition/diffusion layer formed during annealing of iron and copper single crystals at $873 \mathrm{~K}$ for a) $0.5 \mathrm{~h}, \mathrm{~b}$ ) $4 \mathrm{~h}$
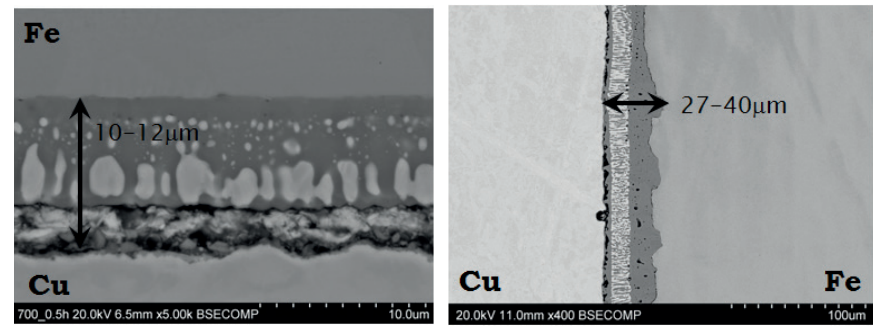

Fig.3. Diffusion layer formed during annealing of iron and copper single crystals at $973 \mathrm{~K}$ for a) $0.5 \mathrm{~h}, \mathrm{~b}) 3 \mathrm{~h}$ 
The interface is characterized by layered-like structure, where the outer-most layers are made of pure $\mathrm{Cu}$ or Fe metals and transition phases in between. The total depth of a diffusion zone varies with time and temperature of annealing from 5 to $10 \mu \mathrm{m}$ in case of a $\mathrm{Cu}-\mathrm{Fe}$ stack kept at temperature of $873 \mathrm{~K}$ for $0.5 \mathrm{~h}$, to about $50 \mu \mathrm{m}$ when the stack was kept at that temperature for $4 \mathrm{~h}$. In case of temperature of $973 \mathrm{~K}$ the zone has depth of about $10 \mu \mathrm{m}$ for $0.5 \mathrm{~h}$ to $27-40 \mu \mathrm{m}$ for $3 \mathrm{~h}$ of annealing (Figs. 2 and 3).

The $\mathrm{Fe}-\mathrm{Cu}$ phase diagram [12] shows peritectic reaction with wide range of concentration for presence of transition phases. Data given in Table 1 imply that diffusion of iron to copper should proceed much faster than in the opposite direction. Thus, an asymmetric interface should be formed, where the transition phase on copper side has larger thickness than that on the iron side. In the situation being described here, another factor is oxygen introduced from air. Diffusion coefficients of oxygen in copper is over two orders of magnitude smaller than in case of iron, thus, two diffusion models will be present in a described system:

1. diffusion of $\mathrm{Fe}$ to $\mathrm{Cu}$ with considerably small influence of $\mathrm{O}$ to $\mathrm{Cu}$

2. diffusion of $\mathrm{Cu}$ to $\mathrm{Fe}$ with simultaneous diffusion of $\mathrm{O}$ to $\mathrm{Fe}$

Therefore, the layered structure of a connection is formed:

- pure copper

- $\quad$ oxide layer on $\mathrm{Cu}$ border (porous)

- a layer rich in copper, iron and oxygen,

- a layer of iron and oxygen with only small addition of $\mathrm{Cu}$

- pure iron.

A layer rich in copper and oxygen, which is a result of diffusion of $\mathrm{Cu}$ to $\mathrm{Fe}$ accompanied by simultaneous diffusion of oxygen what should enhance diffusion of copper. EDS analysis of layers composition shows that oxygen diffusion to iron is more intense than to copper and reached twice bigger distance.

It is known that alloying addition causes decrease of stacking fault energy (SFE) of metal. The smaller the SFE, the easier process for formation of defects in crystal lattice, what enhances diffusive transport of mass. Therefore, diffusion of copper to iron operates as a catalyst for introduction of oxygen to iron-rich phase. Analysis of diffusion coefficients of Fe to $\mathrm{Cu}$ and $\mathrm{Cu}$ to $\mathrm{Fe}$ should not exceed $50 \%$. On the other hand, a dominant layer formed with advantage of penetration of $\mathrm{Cu}$ and $\mathrm{O}$ to Fe lattice with almost total lack of transition phase due to diffusion of iron to oxygen is present in the discussed case.

Temperature and time of heat treatment are observed to affect the height of a layer containing irregular $\mathrm{Fe}-\mathrm{Cu}$ phase (3 to $5 \mu \mathrm{m}$ ). All the EDS measurements, linescans (Figs. 4,6,7,9), point analyses (Fig. 5 and corresponding Table 4), and surface analyses (Fig. 10), show unambiguously that oxygen diffuses profoundly to phases containing iron with copper. Oxygen tends to form ironoxygen phase (dark-grey), where only small amount of $\mathrm{Cu}$ atoms (usually below $2 \%$ see table 4 ) had entered. A much smaller concentration of oxygen is found in $\mathrm{Cu}$-rich phase (about 70 at.\% of $\mathrm{Cu}$ ). Besides, the concentration of copper is higher between branches of $\mathrm{Cu}$-rich $\mathrm{Fe}-\mathrm{Cu}-\mathrm{O}$ phase but this may be caused by overlapping of O-rich $\mathrm{Fe}-\mathrm{Cu}-\mathrm{O}$ phase by an electron beam. It is also worth noting, that oxygen did not diffuse into bulk single crystals of both copper and iron at the studied temperatures.
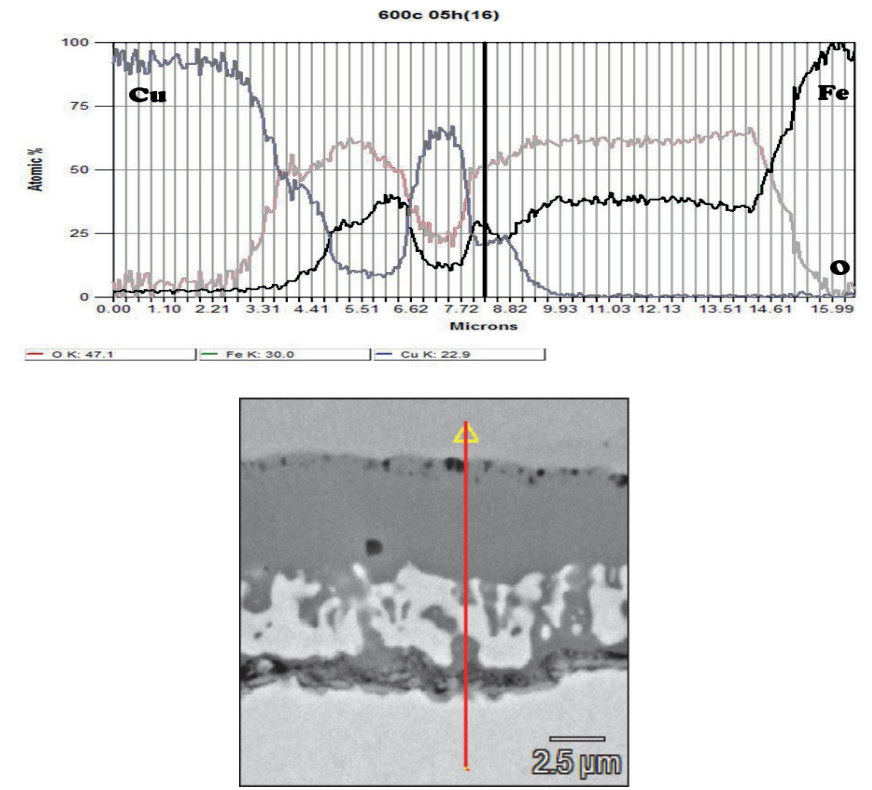

Fig.4. EDS linescan analysis of a connection formed during annealing at $873 \mathrm{~K}$ for $0.5 \mathrm{~h}$ a) concentration profile in at. $\%$, b) position of an analysis path through the connection

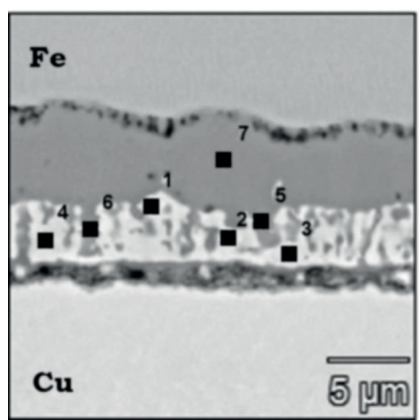

Fig.5. Example of point analysis performed in copper/iron diffusion layer formed during annealing at $873 \mathrm{~K}$ for $0.5 \mathrm{~h}$
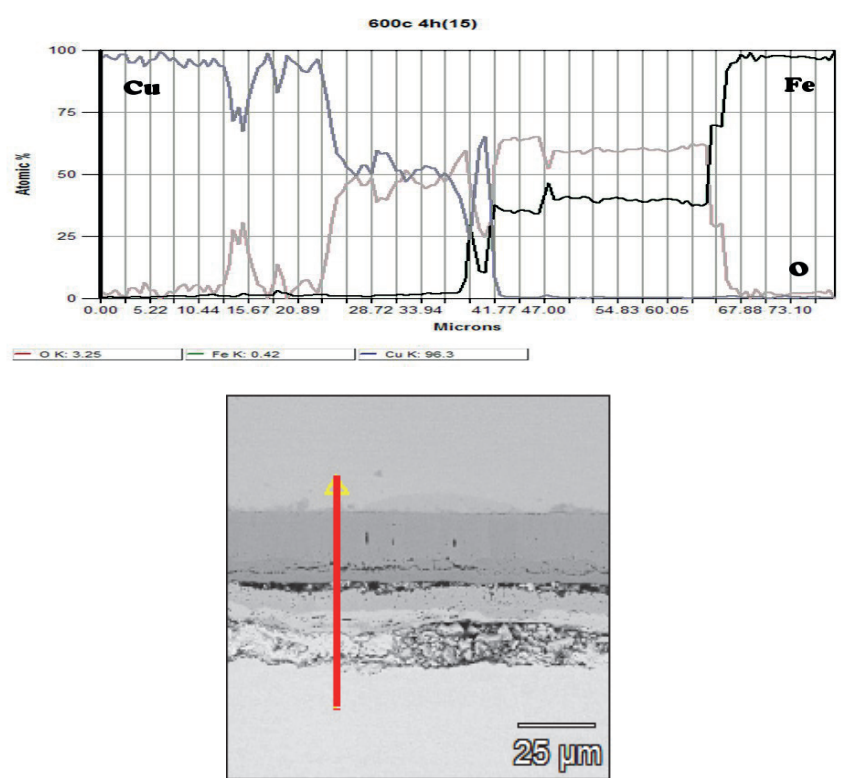

Fig.6. EDS linescan analysis of a connection formed during annealing at $873 \mathrm{~K}$ for $4 \mathrm{~h}$ a) concentration profile in at. $\%$, b) position of an analysis path through the connection 
TABLE 4

Table with EDS results corresponding to the points marked in Fig.5

\begin{tabular}{|c|r|r|r|}
\hline \hline $\begin{array}{c}\text { Point of } \\
\text { analysis }\end{array}$ & $\mathbf{O}$ & $\mathbf{F e}$ & $\mathbf{C u}$ \\
\hline $\mathrm{pt} 1$ & 17.00 & 13.09 & 69.91 \\
\hline $\mathrm{pt} 2$ & 14.54 & 9.01 & 76.45 \\
\hline $\mathrm{pt} 3$ & 6.36 & 4.62 & 89.02 \\
\hline $\mathrm{pt} 4$ & 11.73 & 16.08 & 72.19 \\
\hline $\mathrm{pt} 5$ & 59.17 & 32.41 & 8.43 \\
\hline $\mathrm{pt6}$ & 53.21 & 21.25 & 25.53 \\
\hline $\mathrm{pt} 7$ & 61.87 & 37.65 & 0.48 \\
\hline
\end{tabular}

It is suspected, that that due to air atmosphere, oxygen enters the structure in directions parallel to a connection surface. A dark layer which is observed in all analyzed cases is an alloy phase of oxygen in iron with small addition of copper atoms (bellow 2 at.\%). Quite often the Fe-O layer includes pores arranged perpendicularly to the interface (eg. Figs. 2b, $9 \mathrm{~b})$. Besides, at the border $\mathrm{Fe}-\mathrm{O} / \mathrm{Fe}$-single crystal another chain of pores is formed (Figs.4,5,8,9,10). Additionally, the connection $/ \mathrm{Fe}$ interface is always decorated with pores (Fig.4,5,8). It is also worth mentioning, the interface is not monocrystalline anymore but consists of large grains growing perpendicularly to the interface (well visible in Fig.8.)
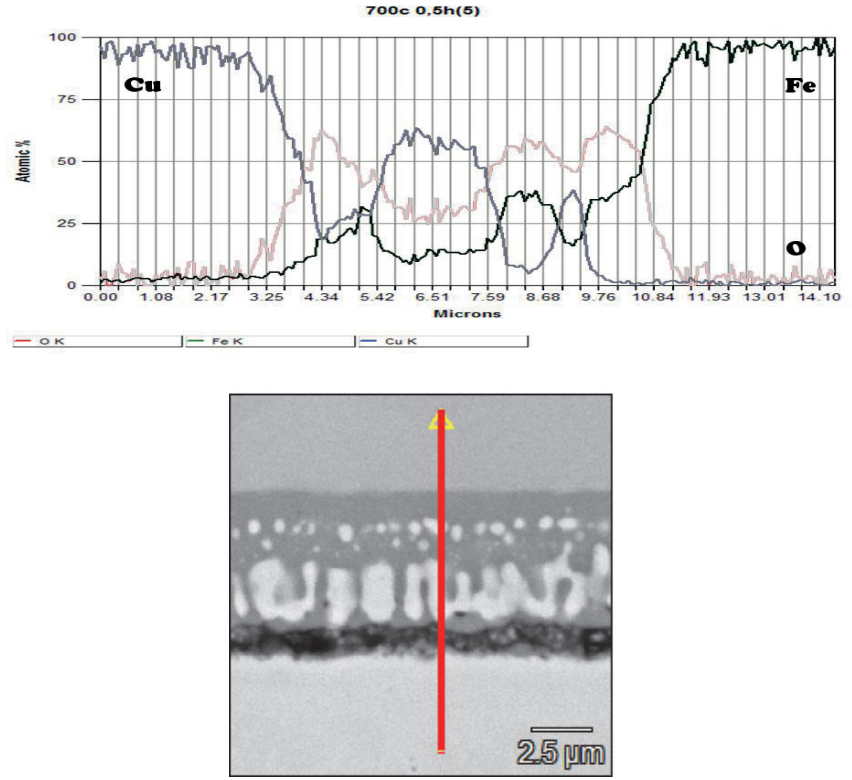

Fig.7. EDS linescan analysis of a connection formed during annealing at $973 \mathrm{~K}$ for $0.5 \mathrm{~h}$ a) concentration profile in at. $\%$, b) position of an analysis path through the connection

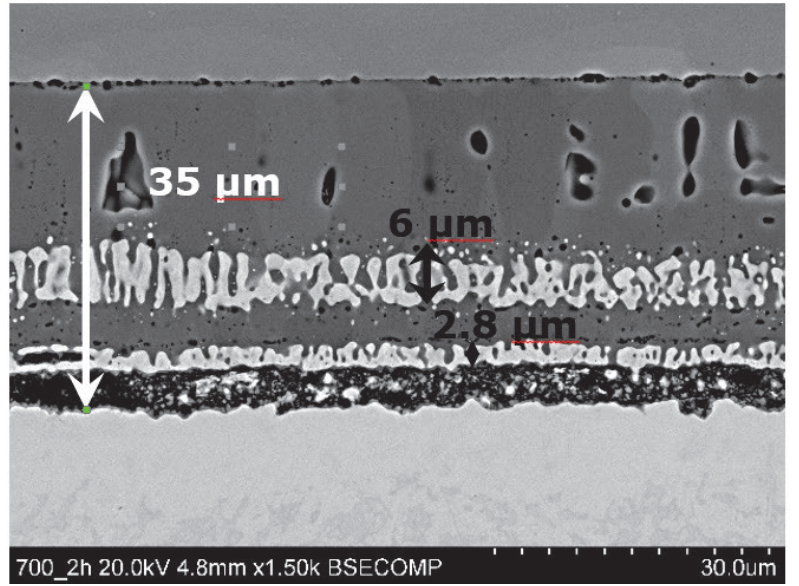

Fig.8. . Diffusion layer formed during annealing of iron and copper single crystals at $973 \mathrm{~K}$ for $2 \mathrm{~h}$
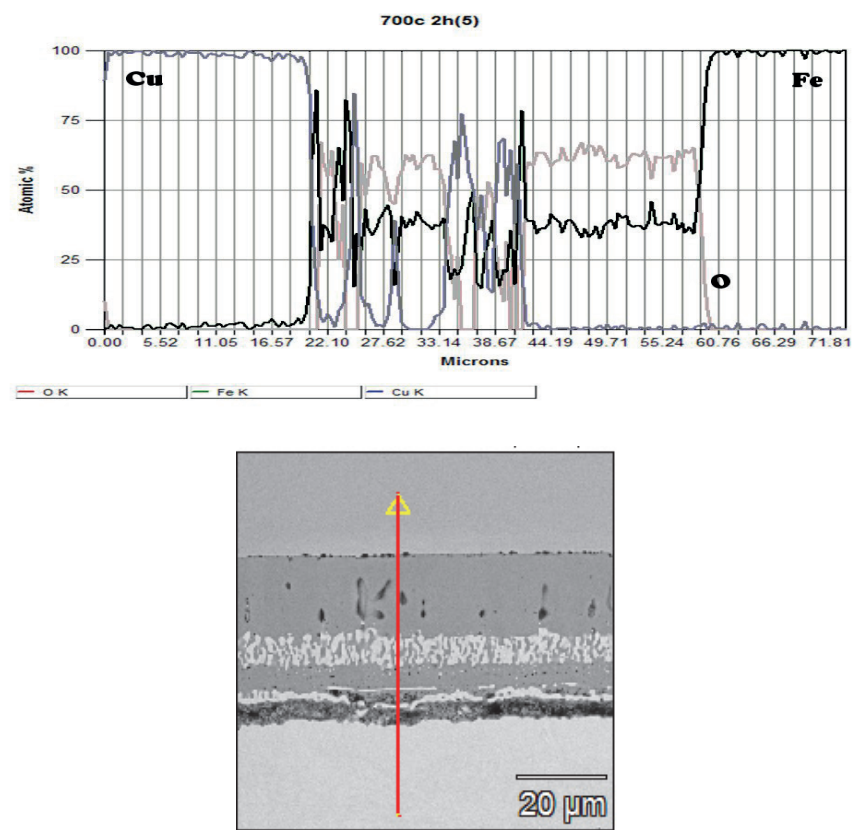

Fig.9. EDS linescan analysis of a connection formed during annealing at $973 \mathrm{~K}$ for $2 \mathrm{~h}$ a) concentration profile in at. $\%$, b) position of an analysis path through the connection
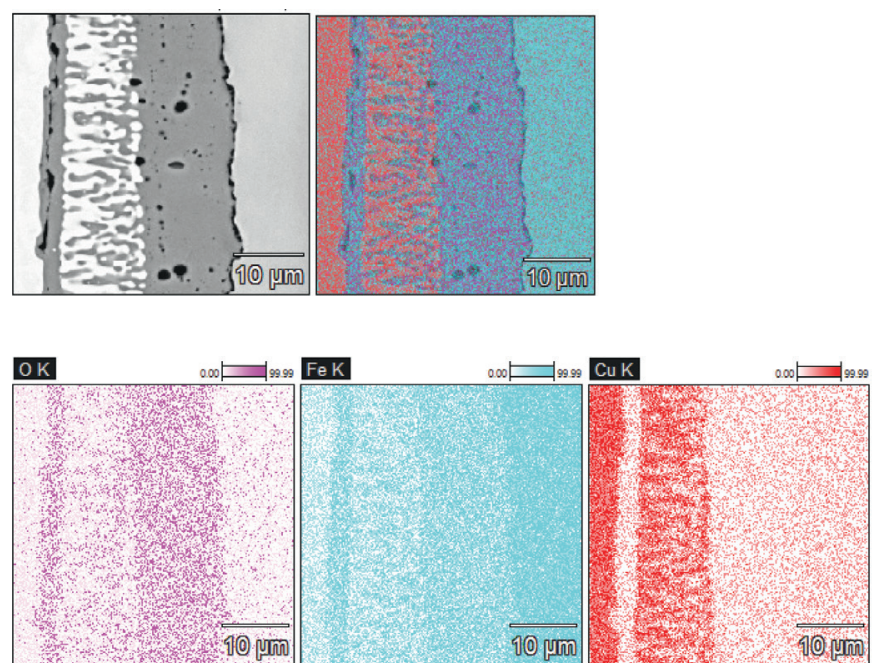

Fig.10. Surface analysis of a connection annealed at $700 \mathrm{C}$ for $3 \mathrm{~h}$; Data Type: at. \% Mag: 3000x, Acc. Voltage: 20.0 kV 


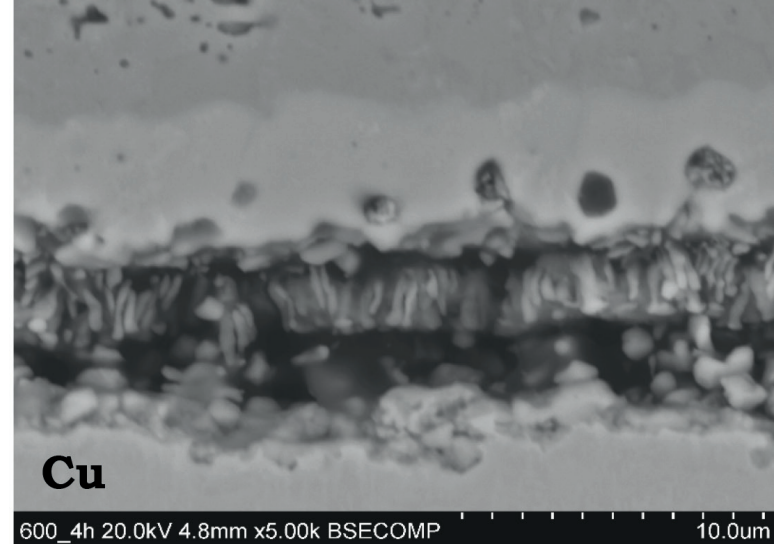

Fig.11. Example of Kirkendall effect observed in the sample annealed at $873 \mathrm{~K}$ for $4 \mathrm{~h}$

Due to difference in value of diffusion coefficients Do of $\mathrm{Fe} \rightarrow \mathrm{Cu}$ and $\mathrm{Cu} \rightarrow \mathrm{Fe}$, the porosity was formed on copper side. This can be connected with Kirkendall effect. An interesting view of the process is presented in Figure 11 with fiber-like forms on the side of diffusion connection.

\section{Summary}

During solid-state annealing form various transition phases: alloy-phases and an intermetallic phase. The nonsymmetric behavior on both sides of connection (on $\mathrm{Cu}$ single crystal side, and Fe single crystal side) is caused by the fact that diffusivity of copper into iron differs from diffusivity of iron into copper. Additionally, it is observed that diffusion does not proceed in continuous manner but forms few solidstate phases which differ in composition but form clearlydistinguished layers. Thickness of connection layer depends on time of annealing and temperature. It is also worth noting that on the copper side, connection exhibits porosity, probably due to Kirkendall effect.
Oxygen appears to have great effect on formation of the connection. The dark-grey layer consists of iron oxide with small addition of copper atoms (bellow 2 at.\%), while lighgrey irregular phase is made from copper (at least 70 at.\%), iron and oxygen.

\section{Acknowledgment}

The financial support of the State Committee for Scientific Research of Poland under the grant number 11.11.180.653 is acknowledged.

\section{REFERENCES}

[1] R.P. Weis, Phys. Rev. 74,1493 (1948)

[2] C. Wells, R.F. Mehl, Trans. AIME145, 315 (1941)

[3] W. Batz, H. W.Mead, C.E. Birchenall, Trans. AIME, 194, 1070 (1953).

[4] R. Linder, F. Karnik, Acta Met. 3,297(1955).

[5] J. Kučera Diffusion in Iron, Iron Solid Solutions and Steels, 'Doctor Habilitatus' thesis, Czechoslovak Academy of Sciences, Brno 1991.

[6] G. Salje, M. Feller-Kniepmeier, J. Appl. Phys. 48,1833 (1977).

[7] G. Salje, M. Feller-Kniepmeier, J. Appl. Phys. 49, 229 (1978).

[8] C. Mackliet, Phys. Rev. 109, 1964 (1958).

[9] M.S. Anand, R.P. Agarwala J. of Appl. Phys. 37,4248(1966).

[10] J. Takada, S. Yamamoto, S. Kikuchi, M. Adachi,Oxidation of Metals, 25, 93(1986).

[11] H. Magnusson, K. Frisk, Self-diffusion and impurity diffusion of hydrogen, oxygen, sulphur and phosphorus in copper, December 2013, ww.skb.se date: 04 May 2015.

[12] T.B. Massalski, Editor-in-Chief; H. Okamoto, P.R. Subramanian, L. Kacprzak, Editors. ASM International, Materials Park, Ohio, USA, (1990). 
